once on a glass slide and examined under the microscope when I found it was a small fresh clot of blood, in which were entangled some ova of the Bilharia haematobia. This examination at once showed the true nature of a puzzling case, and clearly indicated that the boy was suffering from bilharziosis, which he had contracted in Pondoland at least five years before.

In connexion with renal disease I wish to allude to the significance of retinal haemorrhage. In this connexion also, although the amount of blood which actually escapes from the retinal vessels is very small, the significance is great, indicating an advanced stage of renal disease, and is of ill omen.

Gastro-intestinal haemorrhages are in some cases very difficult to explain. Apart from blecding due to actual ulceration, we are familiar with haematemesis, which occurs in the early stages of splenic anaemia or from the rupture of an oesophageal varix in cases of alcoholic cirrhosis of the liver. Stadelmann' has recently shown that some cases of obscure gastro-intestinal haemorrhage are due to the rupture of idiopathic vairicose veins which may occur in the stomach, in the small intestinc, and in the rectum. Dr. Hale White has drawn attention to a special form of bleeding from the stomach which he has named gastrostaxis. In this coudition when the stomach has been opened at an operation the blood has been found to be oozing from an area of congested mucous membrane. Dr. White ${ }^{2}$ has suggested that such haemorrhages may be due to injury of the vessels in the mueous membiane by an endothelial toxin.

I wish in passing to call attention to the very profound secondary anaemia and prolonged ill-health which arises in some cases from small repeated haemorrhages, of almost daily occurrence, from haemorrhoids; the haemorrhage has been neglected by the patient and allowed to go on unchecked for years before, medical advice is sought In these cases the haemorrhage is not of importance as an indication of disease nor on account of the amount lost on any single occasion. It is the repeated small losses which impose so great a st:ain upon the blood-forming organs that a profound secondary anaemia results. The occurrence of these haemorrhages is not mentioned by the patient, perhaps from feelings of diffidence, and it is astonishing how long they are tolerater without com. plaint.

I luave not spoken at all of hacnorthages arising in liaemophilia, purpura, and allied diseases. These are generally recognized, and it is not necessary for me to do more than mention them. I have dealt only with a few aspects of what is a large and important subject, and one of general interest, and time will not permit me to go into the question of treatment, as my object has been to clirect attention to the importance of arriving at a correct diagnosis in every case of obscure haemorihage, so that the riglit treatment may be applied.

REFERTNCEs.

1 perl, lelin. Whoch. May 5th, 1913; Butrise MLedcal Jocirsal, Epitome, October 18th, 1913, 2 L ancet, February 17th, 1912.

THE Khedive has founded a special hospital at Alexandria for the radical cure of hernia. The hospital will be housed in a pavilion of the great institution known as the Abbassi Asylum. It is to be called the Abbas I Hospital, and is to be under the surgical direction of Dr. Colloridi Bey.

A SCHOOL for health officers has recently been organized in connexion with Harvard University and the Massachusetts Institute of Technology. The organization of this school marks, it is said, a distinct epoch in tho American Public Health Service. By the co operation of the two institutions it will be possible for properly cualified persons, on payment of an annual fee of $£ 50$, to be admitted to all the resources of the Harvard Medical School and other departments of that university, as well as to the chemical, biological, sanitary, and engineering oppor tunities offered by a great modern technical school. No derree will be awarded on the completion of the course, but a certificate of public heatth (C.P.H.) will be given fo all who go through the conrse satisfactorily. No degree is reguired for admission, but no one will be admitted who has not completed at least two years of ordinary college work, including chemistry, physics, biology, and Fremeh and German, or who is not otherwise specially qualifled. Professor M. J. Rosenan of the Harrard Medical school is the Director.

\section{A (arture}

\section{THE FIRLY DIAGNOSIS AND OPERATIVE TREATNENT OF CARCINONA OF THE CERTIX. \\ Delivered at the Cancer Hospital, Bronpton.}

HAROLD W. WILSON, M.S., F.R.C.S., ASSISTANT SURGEON TO ST. BARTHOLOMEW'S HOSPITAL AND TO THE CANCER huspital.

Is my work at this hospital I have been struck by the hopelessly advanced stage of the disease in many of the patients who have applied for treatment of carcinoms of the cervix for the first time, and in the ordinary methods of dealing with it there seems to be a lack of the thoroughness and cleanness of dissection which have been applied with such success to the eradication of cancer in other more exposed and accessible organs, such as the breast and the tongue. It is therefore to the great importance of early and accurate diagnosis, and to modern lines of treatment, that I chiefly wish to direct your attention.

The cervix may be divided into:

1. That part which lies free within the cavity of the vagina and is covered with the stratified squamous epithelium of the vaginal mucous membrane.

2. The supravaginal portion, which lies embedded in the lowest portion of the pelvis in the mass of loose connective tissue called the parametrium.

This anatomical classification forms a very useful basis in discussing carcinoma. For the disease beginning in these two portions not only cliffers in its pathologioal characters, both macroscopic and microscopic, but also in its zone of spread, its liability to infect the neighbouring lymphatic glands, and, I think, to a certain extent also in its ultimate prognosis.

('linical Trpes and their Methon of Spread.

Carcinoma arising from the free surface of the corvix grows partly ontwards as an exuberant proliferating mass, partly downwards into the fibro-muscular stroma as long branching columns of atypical epitleclial cells. Depending upon which of these two modes of growth is the more obvious, certain clinical pictures result, and an intimate linowledge of their appearances is essential for accurate diagnosis. Upon the early onset or otherwise of fatty necrosis of the growth also depends the stage at which ulceration or the production of carcinomatous cavities is produced. At the same time it must be admitted that all these processes go on side by side, and it is by the predominance of any one of them that we are enabled to make use of the following arbitrary classification.

\section{A. Carcinoma of the Faginal Cerri.r.}

1. Papilliferous Form.-Here a sessile protuberant growth projects from one or both lips of the cervix into the cavity of the vagina. The specimen I show you here more closely resembles one of those beantiful villous tumours of the bladder than anything else. This, how. ever, is exceptional. The surface of the growth is usually concealed by a yellow sloughy mass, bathed in a pool of muco-pus.

2. Infiltrating Form.-Here the cervix is cnlarged and becomes a cartilaginously hard, shapeless mass, with usually a certain amount of superficial ulceration of the overlying mucous membrane. On section, it is seen to bo occupied by an opaque white growth.

3. Ulceratice Form.--Here the disease may show itself either as (a) a shallow vlcervending to spread outwards on to the vaginal vault, with little intiltration of the underlying tissue; or (b) a craterifor'm cavity with hard everted edges occupying the former position of the cervix, the vaginal portion of which may have completely disappeared.

Methods of Siprear.

Carcinoma of the exposed portion of the cervix tends to spread downwards into the ragina, and ontwards into the lowest portion of the parametrium. Although it 
may occasionally extend upwards along the cervical canal, it hardly ever progresses beyond the internal os, so that the body of the uterus escapes, except perhaps in the very late stages of the disease. The papillifarous type extends outwards over the surface of the vaginal fornices, and may occasionally give rise to a small metastatic deposit in the lowest portion of the anterior vaginal wall. It is this variety also that occasionally gives rise to that curious condition known as "contact cancer"- that is to say, a growth arises in the vaginal wall at a point where the primary carcinoma directly impinges upon it, and appears to have no direct connexion, even by lines of infected lymphatics, with the original focus.

The infiltrating form gradually exterds outwards to the periphery of the cervix, invades the posterior portions of the lateral parametrium, and then has two lines of lymphatic extension open to it:

(a) Directly outwards to the lateral pelvic wall with infection of the lymph glands in this region.

(b) Dorvnwards into the subcutaneous tissue of the vagina, where, for a time, it remains covered with intact mucons membrane. The bladder and rectum are involved later by direct extension, but metastatic growths in the viscera are almost unknown.

B. Carcinoma of the Supravaginal Cervix.

The disease here begins in the mucous membranc lining the cervical canal, and the smooth walls of the latter are rapidly converted into a rongh, nodular, and easily bleeding surface. The muscular tissue of the cervix becomes replaced by a mass of growth which soon undergoes necrosis. Degeneration begius, either on the free surface, and is then shown as a gradual lecpening process of ulceration, or centrally, when the abscess thus formed soon bursts into the cervical canal. In citiner case the enlarged and massive cervix is replaced by a suppurating cavity with thin infiltrated walls.

\section{Methods of Spread.}

Upward extension into the body of the uterus is here frequent, whilst direct passage downwards through the external os to the vagina is almost unknown. The internal os seems to be no bar to the extension of the disease, and the carcinomatons process sometimes appears to glide upwards in the mucous membrane, until in some cases the whole of the lining membiane of the body of the uterus has apparently taken on malignant characters.

The periphery of the cervix reached, the growth spreads rapidly outwards and downwards in the lymphatics of the parametrium, and infection of the internal iliac glands ensues at an earlier period than is the case when the disease attacks the vaginal cervix. The base of the bladder is invaded early by direct extension, whilst rectal involvement only occurs in the terminal stages.

Difficulties in Early Diagnosis.

1. Those due to the Character of the Disease.-In its early stages carcinoma is a painless disease. When the cervix is the organ attacked, the patient will receive little or no warning of its presence, until ulceration is well established and infection of the grow.h with pyogenic organisms has orcurred. Until this fact has been thoroughly inculcated into the lay mind, no early cases of cancer will come to the surgeon for treatment, except those in which the disease is accidentally discovered during a medical examination for some other, perhaps trivial, complaint. A patient with a carcinoma of the breast will first come for treatment months after she has dis. covered the existence of a hard lump, and yet has not realized the seriousness of her condition because she has suffered no inconvenience or pain. If this is the case when cancer attacks an organ so closely under the patient's own observation as the breast, it is not surprising that we find the disease in a more adranced stage in the case of growths of the uterus.

2. Those due to the Patient.-Even when the danger signals of bleeding and discharge clearly warn the patient that something is wrong, it is almost inconceivable how she will temporize and delay consulting her medical attendant, whilst precious weeks and even months are allowed to go by. Again, slight irregular vaginal haemorrhages and discharges are so common during her menstrual life, especially towards its close, that a woman is often disposed to regard them as of trivial importance only. So, indeed, they may be, but the doctor is the only safe judge of this. Many women are ashamed or are afraid of the discomfort and pain of the dreaded examination, and will - leave no stone unturned, and regard no pretext or excuse too trivial, to avoid it. Others, again, perhaps already suspect the nature of their trouble, and dread the confirmation of their fears and the strong recommendation for surgical interference which must necessarily follow. The ideal thing would be to examine, as a matter of routine, all patients complaining of gynaecological symptoms; but this, at the present day, I know to be an impracticable suggestion to the general practitioner. There are, however, three symptoms which, if not exactly pathognomonic of carcinoma, are at least strongly suggestive of its presence. In a case in which one or more of these symptoms aro present a complete examination must be insisted upon, and no excuse regarded as sufficient even to delay or postpone it. When a patient complaining of these symptoms consults me, it is my practice to assume that malignant disease is present, until, by a complete examina tion, utilizing every known means at my disposal (in. cluding microscopic examination of a portion of the tissue if necessary), it is possible to satisfy myself that such is not the case.

Symptoms Indicative of Carcinoma of the Cervix.

(a) The first and most important of these is bleeding on coitus. If this is present in a marked degree it is practically diagnostic of carcinoma. No other disease, with the possible exception of a large erosion or a mucous polypus, will give this symptom, and they only rarely; when it occurs, it is little more than a slight staining of the mucoid secretion. A word of warning is necessary here. A patient will complain of bleeding, but her natural delicacy of feeling will often cause her to omit to mention exactly when it occurs, and this portion of the history will only be elicited by a leading question. The haemorrhage is caused either by mechanical iujury and the breaking off of small picces of friable growth during the sexual act, or by the rupture of a small vein or artery as the result of the active engorgem $2 n t$ of the pelvic vessels which takes place at this time.

(b) Metrorrhagia occurring several months after the menopause. After menstruation has ceased, several clear months elapse, and then the patient begins to suffer from irregular haemorrhages. This is strongly indicative of the presence of carcinomia. It is quite a different thing from bleeding taking place actually at the time of the monopanse, which is by no means an uncommon occurrence. This also, of course, may be caused by a growth, but in many cases no definite cause can be assigned to it. 'That it is due to some definite pathological lesion is certain, yet in many cases it is difficult to identify exactly what this is, and, as many of these patients completely recover in a few months and remain well for years afterwards, it is obvious that in their cases it cannot portend anything very serious.

(c) A somewhat profuse serous discharge, which is usually blood-stained. This occurs in some early cases of carcinoma of the supravaginal cervix, and as it is unusual in any other condition it may prove a very valuablo indication. Students are too much inclined to rely upon the age of the patient and the signs of prolonged septic intoxication as a means of diagnosis. Suffice it to say that carcinoma of the cervix may arise at any period of life between 25 year's and extreme old age, and when "cancerous cachexia" is established, the local signs of tho disease are only too obvious and the growth far boyond the reach of surgery

3. Those due to the Many Different Forms the Disease may Assume.-The symptoms mentioned above must be regarded as being a mere indication that a given patient may be suffering from cancer. 'The actual diagnosis can only be made upon the sound basis of physical signs, and to appreciate these a thorough knowledge of the pathological appearances of the disease is essential. If carcinoma attacks the vaginal portion of the cervix the diagnosis is usually not so difficult, because here the growth can actually be seen as well as felt. Both these methods of examination should be employed. Early cases are often best identitied by means of a good light and a speculum. 
whercas in later cases with extensive subvaginal spread and an intact covering of epithelium the extent of the disease may only be realized by palpation. When, how ever, it is the supravaginal cervix which is affected, the external os remaining closed, a correct diagnosis can only be arrived at by a combined bimanual and rectal examina. tion, made under an anaesthetic if necessary. In these cases the tissues of the vaginal roof are often tense and resistant, and a bimanual vaginal examination alone is not satisfactory. It is only when the examining finger is passed high up the bowel along the anterior wall of the rectum, and the affected portion of the cervix palpated between this and the opposing land pressed deeply into the abdomen, that a correct estimation of the actual condition of affairs can be attained. 'The disease may, of course, have spread downwards and involved the lower portion of the cervix, or the external os may be open. In these circumstances no special difficulties will be encountered. There are two important factor's to remember in the diagnosis of this disease.

(1) The Enlargement of the ('crvix.-The presence of a neoplasm will almost alway's give rise to some enlargement of a part or the whole of the cervix. This may be evident either as a proliferating growth on the vaginal surface, or as an increase in the actual diameter of the cervix, which may retain, to a certain extent, its natural shape and contour. In the latter case the growth may be limited to one side of the cervix, crowding the cervical canal over to the opposite side, or the change may be a uniform one. The cervix becomes cartilaginously hard, and at the same time gives an impression of solidity which is not found in chronic inflammatory cervicitis. As the growth invades the lymphatic spaces of the parametrium the cervix loses its smooth regularity of ontline, and this chat ge will be the better appieciated if the disease is limited to one aspect of the cervix, and the healthy side is avail. $\mathbf{b}$; for comparison. A gradual loss of the normal elasticity of the tissues at the side of the uterus is observed as the disease extends: eventually a massive nodularity replaces the thin layer of parametrium, through which, under normal circumstances, the fingers can easily be made to meet on bimanual examina tion. Inflammatory thickening of this region is not un common, and it may be exceedingly difficult to distinguish between these two conditions. The latter is usually recognizable as a flattened fibrous band passing outwards above the roof of the lateral fornix to the pelric wall. Malignant infiltration gives an impression of greater solidity, with its deepest portion at the side of the cervix gradually fading away as the pelvis wall is arproached. When, however, it is remembered that carcinoma may arise in an organ already fixed by inflammatory changes, and that peri-lymphatic fibrosis, to a varying degree, in. variably takes place around the adrancing columns of cancer cells, it will be appreciated how difficult it may be to give a correct interpretation to the physical signs in a given case. Even with the abdomen open, it may be almost impossible to say how much the changes found are due to inflammatory, how much to cancerous infiltration. Coincident with this lateral spread into the loose pelvic tissues is usually a gradual enlargement and characteristic induration of the vaginal cervix. As the growth approaches the surface the overlying mucous membrane gradually thins and assumes a bluish coloration. It iventually gives way, and an extensire shallow ulcer, with an indurated base, becomes evident.

(2) Friability and Ulceration.-By friability is meant a curious brittle and crumbling character of the tissues which ensues as the result of fatty necrosis of the growth. Any roughness of the examining finger or sound will break off small portions of the carcinomatous tissue. This is absolutely diagnostic, as no other disease will give this currious sensation. With this there is usually a certain amount of bleeding, and even somewhat forcible distension of the upper portion of the vagina with a specu'um may produce quite an alarming amount of haemorrhage.

When both these factors, induration and friability, are in evidence, a correct opinion will probably soon be arrired at. If, however, only one of them is present, an indurated cervix without loss of its epithelial covering, or a shallow ulcer without an indurated base, the microscope alone can decide. The sharp-cut and somewhat irregular edge, and the indurated bright red or slonghy base, of the typical carcinomatous ulcer of the vaginal cervix forms a distinct and, as a rule, characteristic clinical picture. But an ulcer of the exposed portion of the cervix may prove one of the most difficult of diagnostic problems. Again, a lacerated cervix containing much cicatricial tissue, with everted, red, and easily bleeding mucous membrane and many distended follicles, will often present great difficulty in diagnosis. In some cases a correct opinion will rest entirely on the histological evidence derived from the examination of a wedge of tissue, cut so as to include the growing edge of the lesion.

If, in a patient presenting suspicious symptoms of carcinoma, the lower surface appears healthy and the external os is closed, its interior must be explored. Forcible dilatation of the os by graduated sounds until the finger can be inserted is, perhaps, the most satisfactory method. Much may be learnt by the way the tissues give way before the gradually increasing sizes of dilators. This metlod, however, is not without its disadrantages, unless the surgeon is prepared to operate without delay if cancer is found. Any mechanical violence of this kind may cause large fissures in the infiltrated cervix and open up the pelvic tissues to pyogenic infection. Thus the technical difficulties of a postponed operation may be increased and the delineation of the actual spread of the growth rendered uncertain.

A safer and almost equally satisfactory method is the insertion of a curette and removal of small portions of tissue for microscopic examination. Here, again, the rough and friable character of the tissue lining either the cervical canal or a carcinomatous cavity communicating with it, and the profuse haemorrhage which follows the removal of the instrument ought to admit of little doubt $i^{n}$ the orciinary case.

Operative Treatuent.

The operations performed for carcinoma of the cervix must be discussed under the two headings of (a) radical, or (b) palliative operations.

(a) Radical Operations.

Even when the abdomen has been opened, the decision as to whether a growth is suitable for removal or not may prove a most difficult question. My own feeling is that, unless an absolutely safe margin of healthy tissue is assurea, no critting operation should be attempted, as stuch procedures serve no useful purpose. The clearing away of Nature's barrier of conservative fibrosis, and the opening up of tissue already infected with carcinoma tends to hasten the spread of the disease, and to shorten rather than prolong the patient's life.

Cases showing extensive vaginal spread or direct bladder invasion are certainly not suitable. The latter mode of extension is more likely to occur when the disease has begun in the supravaginal cervix, and the heaped-up and oedematous condition of the overlying bladder mucous membrane which results in the earliest stages will be best identified by the use of the cystoscope. The most satisfactory way of examining for extension into the posterior part of the lateral parametrium is by bimanual rectal eximination under an anaesthetic. If, at the same time, an assistant pulls the cervix well down into the orifice of the vulva with a volsellum, the earliest change of loss of elasticity will be discovered. At the same time, this test must only be regarded as a measure of the tech. nical difficulties likely to be met with at the operation. A clinically healthy parametrium does not preclude a microscopic invasion of its lymphatics, and, conversely. a previous puerperal parametritis may result in absolute fixation of t'ie uterus.

If, under an anaesthetic, the iliac glands are already palpable, it may be safely assumed that they are markedly enlarged. This is not a point of great practical impor. tance. Glands with no sign of enlargement can be histologically shown to contain carcinoma; whereas, on the other hand, inflammatory masses in this disease are not unusual. In deciding whether a casiz is suitable for a radical operation or not, every surgeon must be a law unto himself. If he feels that he can cleanly and com. pletely remove the whole of the disease by a procedure of such an extent as will offer the patient a reasonable prospect of recovery, and at the same time allow her later 
to take up her position again in the social world, the operation ought to be performed.

Modern vaginal section, which differs from that of ten years ugo in that the manipulations are carried out under control of the eye, has an assured position in the surgery of the disease. This operation is being extensively used on the Continent at the present time. Admitting that the removal of the parametrium cannot be so complete, and that the lack of exposure precludes any clearing away of the lymphatic glands on the lateral pelvic wall, still in proper hands it will remain the operation of choice for some cases. In an elderly bronchitic patient, with the disease still clinically confined to the uterine tissue, the shorter time necessary for its performance and the much less shock experienced by the patient are very strong points in its favour. In fat women also this operation presents many advantages. Its ultimate results will not compare very unfavourably with those of the abdominal operation. With these exceptions the abdominal route will, in the great majority of cases, be the operation of choice.

Extent of the Abdominal Operation.

All surgeons will agree that the scope of the operation ought to include the removal of all the nterine tissue, a cuff of the upper third or half of the vagina, and the whole of the parametrial tissue in the broad ligament, and, lower down, at the sides of the cervix. The point under discussion at the present day is how far the operation should further proceed in the cleaning of the lateral pelvic wall and removal of the iliac glands. This certainly prolongs the time of operation considerably, and opens up a dangerous amount of loose tissue to sepsis, which is practically always present. Again, it means that the ureter must be cleaned and isolated for the entire extent of its pelvic course, and although the textbooks show beautiful pictures of it left attached to the peritoneum and intact in its sheath, this is not possible under ordinar'y circumstances. It has been my practical experience that the close of the operation finds the ureter hanging loose across the pelvis, and that this entails an appreciable risk of post-operative sloughing, and the formation of a ureterovaginal fistula some eight days or more later. Even if this does occur, however, it is not a great price to pay for a complete eradication of carcinoma in this region. In a consiclerable proportion of these cases the fistula closes of itself and gives rise to no further trouble.

When discussing the pathology of the disease, it was pointed out that giandular infection usually occurred late. Although it is impossible to give accurate figures at the present time, probably in some 80 per cent. of the cases in which the parametrium is clinically free, no microscopic evidence of carcinoma will be found in the iliac glanils. Exceptionally large masses of infected iliac and lumbar glands are found where no palpable extension of the disease at the sides of the cervix is appreciable.

Bearing these facts in mind, the rules which I have adopted for my own guidance are as follows:

1. The iliac glands are not removed if, after the abdomen has been opened, they are not found to be enlarged, and the parametrium is clinically healthy.

2. If the patient's general condition is good and the parametrium is clinically infected, whether the iliac glands are enlarged or not, the larger operation is performed.

3. If a large mass of iliac glands is found, the operation is not proceeded with. By this time infection has spread far up the ovarian lymphatics to the lumbar glands, and no operation will cure the patient of her clisease.

(Lantern slides were then thrown upon the screen illustrating the different stages of the abdominal operation adrocated, and specimens of the disease removed in this way.)

(b) Palliative Operations.

Something can be done, in an advanced case of the fungating type of growth where a large mass fills up the vagina, for a patient suffering from pain, a profuse, purulent vaginal discharge, and haemorrhage. Of the various methods of treatment employed, none are better than a thorough use of the cautery, and the removal of all the exuberant portions of the growth by this means. The diathermic cautery is the best instrument to employ, as the extent of its action is rnuch more under the control of the surgeon than is the cass with the actual cautery.
The necrosis also, which the former instrument produces, is much less likely to be followed by an intense inflam. matory reaction at the periphery of the growth, or by bursts of secondary haemorrhage later as the sloughs separate.

Ligature of arteries is also useful in those cases in which haemorrhage and discharge are the prominent features. If the abdomen has been opened for the exploration of a growth which subsequently proves to be inoperable, it is quite a simple matter to ligature both main internal iliac arteries and one or both groups of ovarian vessels. This will cause a marked improvement in the symptoms for a time, but the results are not sufficiently permanent to justify a laparotomy for this procedure alone.

\section{THE INELCENCES OF VENEREAI. DISEASES.}

Delivered Before the Liverpool Medichl Isstitction, November 20Th, 1913.

\section{BY CHARLES J. MACALISTER, M.D.EDIN.,} F.R.C.P.Lond.,

HONORAIY PHYSICIAN, ROYAL SOUTHERN HOSPITAL, AND TO THE ROYAL LIVLRPOOL COUNTRY HOSPITAL FOR CHILDREN, HESWALL, ETC.

AFTER some general observations on the influence of public opinion on morality, Dr. Macalister continued as follows :

The Contagious Diseases Acts, so far as this country is concerned, had their day, and proved to be worse than useless, and it seems likely that other countries, in which the regulative systems originated and have been more deeply rooted, if they have not already abolished them are likely, following the lead of England, to do so in the near future, and that some really effective means of endeavouring to stamp out the trouble will becomc adopted among the more advanced civilizations. This is the more likely as the importance and far-reaching effects of both diseases are becoming more and more evident. After these Acts were repealed it became clear that some diminution in the amount of venereal diseases took place, at all events, so far as syphilis was concerned. It was difficult to prove this with reference to the general popu. lation, but the evidence derived from the army statistics was very definite, because under the Acts special provision was made for the soldier; and it was significant enough that the parliamentary returns showed that when these regulations were rescinded, after a short temporary rise in the figures, there was a progressive decrease from 275 per 1,000 admissions in 1885 to about 19 per 1,000 in 1900. The soldier since those days has been educated and warned concerning the dangers attributable to venereal diseases, as he has been with reference to the evils connected with drink, with the result that he is in every sense a more moral, a more temperate, and a much more respectable member of society now than he was then. With reference to the general population, what can we say? Only this, that whatever improvement took place after the repeal of the Acts-and there probably was a good deal-the amount of syphilis and of its results continues to be simply appalling. In the light of modern knowledge it seems evident that no sub. stantial decrease in the disease is at present occurring, but that it is probable that an alteration has taken place in its type; and, furthermore, it is certain that a growing number of diseases which were not formerly considered to be syphilitic in origin-or, at all events, were only suspected to be so-are now definitely known to be due to that infection. The literature of syphilis and our experiences of it in the hospitals amply testify to the widening of the importance of this disease, and to the serious part which it is playing as a destroyer of the general health of the people, as an enfeebler of domestic health and wealth, leading as it does to chronic invalidism or death of parents when their children are still young, and damaging the childhood of the nation to a degree which is only beginning to be fully recognized. There is no possibility of arriving at accurate figures in this country, owing tc the way in which the disease is hedged round, but we can gather some estimate of its extent from figures furnished 